\title{
Modeling Dependent Structure Among Micro-Economics Variables Through COPAR (1)-Model in Pakistan
}

\author{
Yousaf Ali Khan ${ }^{1,2}$ iD
}

Accepted: 28 December 2021 / Published online: 27 January 2022

(c) The Author(s), under exclusive licence to The Indian Econometric Society 2022

\begin{abstract}
A great fluctuations in oil price due to COVID-19 has been observed worldwide. Expertise of complicated relationships among economic indicators has considerable significance for consumers, specialists and strategy producers the same. This exploration work is devoted to investigating the impact of oil price fluctuations due to corona virus pandemic on inflation rate, interest rate and industrial production during lock-down using recent monthly data of Pakistan economic system starting from 2008-01 to 2020-04. At analysis stage, we generally tend to contemplate a novel autoregressive model approach to model non-linear dependence structure amongst a couple of time series. Having gain from the flexibleness of R-vine copulas, the copula autoregression with efficiency investigates the have an impact on of one-time series onto some other: it really is, one-time arrangement normally plays a vital role. Through these qualities of the model, we tend to investigate fuel price effects on industrial production, expansion rate and interest rate in my homeland. One in every of the key finding of this analysis is that there's a weak tail asymmetry, however some tail dependence, that COPAR-model with efficiency absorbs to account. Furthermore, the fashions monitor lagged reactions of interest rate and industrial production on adjustments in fuel prices inside Pakistan. The oil price result on the inflation rate; on the other hand, is quite rapid.
\end{abstract}

Keywords Problem structuring · Copula autoregressive model · Dependence structure $\cdot$ Inflation rate $\cdot$ Industrial production $\cdot$ Multiple time series

Yousaf Ali Khan

yousaf_hu@yahoo.com

1 Present Address: School of Statistics, Jiangxi University of Finance and Economics, Nanchang 330013, Jiangxi, China

2 Department of Mathematics and Statistics, Hazara University Mansehra, Mansehra, Pakistan 


\section{Introduction}

Energy has an essential position in the global economic system. Regardless of the substantial need of alternates of power, e.g., wind energy, water, nuclear, and optional energy, some percentage of oil in financial matters has no longer declined to this point. Oil contracts are designated in U.S. dollars; the discrepancy in fuel costs consists of the basic conflicts on the conversion scale of oil imports to worldwide exportation areas, yet Dawson (2007). Explosion in oil charges causes high liquidity, increment in resource expenses, high consumer charge motivation increment in inflation. An oil shock is the most basic strain; now, it is not without doubt oil shippers, however conjointly the oil maker's experience. It affirms negative effects on the worldwide monetary framework, causing budgetary hopelessness, particularly in industrialized countries such as (Germany, USA, Japan, France, USA, and so forth.) that are exceptionally relying upon oil, the premier shippers of oil. Upward impulse in oil costs is supposed to process the increment inside the oil exportation states' cash surpluses, fundamental to a basic modification of the example of paying and risk. On each event, disappointed in oil costs rise; oil exportation global areas need to experience massive and shocking outcomes because of the change in liquidity that is equipped for presenting a lift to capital controls, reduce the board on esteem devotion, and justification to increment in inflation; fundamental to the devaluation of cash value Dawson (2007). As inflation rate, loan costs, stock returns, exchange rates, industrial production, and numerous others are impacted by oil costs and are encased in the planning of some traders, and the reliance measure is far basic to identify. Oil is found that essentially filed things in this way traders get the addition of it to manage risks, Sari et al. (2010).

Although a collection of studies examined the causal connections between financial matters and money influences, oil value, exchange rates, gold price, stock returns, and rate of interest for different economies. Sari et al. (2010) uncovered entirely short-term relations among valuable metals costs, oil cost and exchange rate. Hussain et al. (2013) observed a double-direction relationship amongst stock profits and fuel cost in Malaya. Jian and Ghosh (2013) demonstrated relaxed associations between worldwide oil costs, important metals, and Indian rupee us dollar. They observed that the gold price does not granger causes exchange rate. Jian and Biswal (2016) investigated the connection between overall gold bar value, oil expenses, cost of trade, and stock returns in India. They established an inverse connection between fuel and gold value rationale to incline in rupee plus stock exchange. Ito (2010) inspected the effect of oil charges on total national output, inflation, and original exchange rate in Russia utilizing co-joining and energy response work. It had been recorded that because of a one percent increment (decline) in oil charges, the expense of trade declines (decrease in value) by utilizing seventeen percent in the long-term and gross domestic product (GDP) declines with the ratio of $46 \%$. In the short run, the total national output increases slightly, whereas the pace of trade declines due to an increase in oil prices.

Several investigations regarding Pakistan's financial system are also available in the literature. Irshad et al. (2012) examined the association between gold price, 
oil cost, and stock returns in Pakistan and concluded that no causal relationship exists among these variables. Mushtaq et al. (2012) investigated the relationship between stock returns and financial instability with the help of EGARCH and LA-VAR in the country. The examination found a bidirectional relationship between foreign direct investment and stock exchange, yet between the stock market value and foreign exchange rate. Aslam (2014) establishes a bifacial connection between the cost of substitutes and KSE-100index in Pakistan. Tabassum and Gulzar (2015) analyzed the connection among exchange rates, inventory rates, foreign reserves, and oil prices in Pakistan and found causal connections among the study variables. They concluded that stock and oil cost granger causes exchange rate, exchange rates influences foreign reserves, stock return ganger causes oil price, and foreign reserve Granger causes stock price. Furthermore, recently, Akbar et al. (2019) evaluated to have a look at the dynamic linkages between interest rate, stock returns, gold rate, and exchange rate in Pakistan with the aid of the use of the Bayesian VAR model. The study observed inverse bilateral relationships among gold price and stock returns, whereas the fine bilateral connection among stock expenses and rupee price.

Since monetary exposure tools are comfortable to stabilize the economic system and, as a result, policymakers are interested in realizing the concept of sensitive concepts related to their objectives. Rate of interest is that the monetary authorities set the essential monetary coverage device, whereas thinking about inflation, investment level, and fluctuations of enterprise manufacturing have direct connections with domestic gasoline prices. Monetary authorities need to respond to these fluctuations via changes in the price of interest. An economy like Pakistan that imports oil to satisfy his everyday consumption demand, wherever eighty percent of electricity is reproduced from liquid oil and oil is traded in U.S. currency fluctuations in dollar rate affects the domestic gasoline prices. However, domestic rate variations upon oil expenses are vital for inventory exchange, individual investors, and companies yet as for economic authorities in the country.

Moreover, economic authorities' response to fluctuations in oil prices and inflation through a dynamical degree of fee of interest may also affect stock returns. For this reason, oil prices, inflation rates, rate of interest, and industrial manufacturing may be thought of as a crucial nexus to be analyzed. The connection of the nexus is attracting interest because of their essential function in alternative markets. Consequently, understanding the dependent structure amongst these variables has importance for policymakers in stabilizing the country economy and portfolio managers.

To the best of our knowledge, no study exists in the literature that includes analysis of the nexus considering using the information of my country's economic system. Furthermore, research realities have analyzed the relationships among gold rate, exchange rates, and different economic variables. Literature shows that the consequences of the interrelatedness of the various variables of the nexus varied and mixed. Vector autoregressive modeling classical framework is employed for prognostication and analysis of linkages amongst these variables. As it is understood to all of us that, VAR models are appropriate when there is a linear and symmetric dependence between time series. Conceptually, the vector autoregressive and autoregressive copula models of this study are equal. However, the COPAR(K) model for 
stationary series with a Markovian structure is also the impression of superior to VAR-model mainly when one or more time series depends on a time series, onetime series normally performs a crucial role. Copula autoregressive model, blessings from R-vine copulas' flexibility overcomes the problem of serial and between-series dependence and lets into nonlinear model dependence amongst multiple time series (see Brechmann and Czado (2015)).

Implementation of the autoregressive copula model has not been typical within the literature due to the rationale that it desires a demanding work of mathematical derivation of probability density along with simulations and specification of a bivariate copula. However, the introduction of the latest computers has made it easier to specify the bivariate copulas amongst variables and conduct simulations correctly and therefore, better effects are likewise received via the usage of the copula autoregressive model. In light of the above discussion, the current evaluation tries to discover the dependent structure of domestic oil price, inflation, interest rate, and industrial production with the more delicate copula autoregressive econometric modeling approach by employing COPAR of order k. Granger causality was investigated among the time series under consideration. Appropriate bivariate copula autoregressive models were then constructed for inflation, interest rate, and industrial production concerning gasoline price to investigate the effect of oil costs. The leg length of the models was selected using BIC, AIC, and HQC. The selected COPAR model was then used to analyze the serial dependence, between-series dependence, and cross-serial dependence among the variables. Hence, the present study may have an extensive contribution in the expressions of a methodological framework to discover the dependence structure of the variables underneath attention in Pakistan using an extra sophisticated technique compared to previous research.

The remaining part of the paper is organized as follows. Section 2, in short, describes the idea of vine copula. Section 3 demonstrates the copula autoregressive model and extension to higher orders. Section 4 provides the application of COPAR to real-life data sets. Section 5 concludes this research. An overview of the considered monthly variables for Pakistan, skewness visualization of the variables, Granger causality among selected time series and bivariate copula families and their order considered in the choice technique for dependence are presented in Appendix 3.

\section{Methodology}

\section{Vine Copulas}

Because the statistical applicability of vine copulas with non-Gaussian built bivariate copulas was diagnosed via Aas et al. (2009), vine copulas became a fashionable tool to explain the reliance structure of multivariate statistics (see Aas (2016) for a recent evaluation). Furthermore, Brechmann and Czado (2015), Beare and Seo (2015), and Smith (2015) have applied vine copulas to model the temporal connection of multivariate time-varying observations as well as the cross-sectional reliance between univariate time series. In this segment, we evaluate the autoregressive copula model of Brechmann and Czado (2015), which explains the stochastic dynamics 
and the time series's reliance structure under consideration. We start with the concept of ordinary vines from Kurowicka and Cooke (2006). We do not forget illustrating examples of pair-copula building and refer instead to Czado et al. (2010) or Aas (2016) for more perception.

Definition 1 (Regular vine) A group of trees $\mathrm{V}=\left(\mathcal{T}_{1}, \ldots \ldots, \mathcal{T}_{\Uparrow-1}\right)$ is a regular vine on -elements if.

1. $\mathcal{T}_{1}$ is a tree with nodes $\mathcal{H}_{1}=\{1,2, . ., \mathbb{\}}\}$ linked by a set of non-looping edges $\mathcal{F}_{1}$.

2. For $\mathrm{i}=2, \ldots,-1, \mathcal{T}_{\mathrm{i}}$ is a linked tree with edge set $\mathcal{F}_{\mathrm{i}}$ and node-set $\mathcal{H}_{1}=\mathcal{F}_{\mathrm{i}-1}$, where $\left|\mathcal{H}_{\mathrm{i}}\right|=-(\mathrm{i}-1)$ and $\left|\mathcal{F}_{\mathrm{i}}\right|=-\mathrm{i}$ are the number of edges and nodes, respectively.

3. For $\mathrm{i}=2, \ldots,-1, \forall \mathrm{e}=\{\uparrow, \mathrm{o}\} \in \mathcal{F}_{\mathrm{i}}:|\uparrow \cap \mathrm{o}|=1$ (two nodes $\uparrow, \mathrm{o} \in \mathcal{H}_{\mathrm{i}}$ are linked by an edge $\mathrm{e}$ in $\mathcal{T}_{\mathrm{i}}$ if the parallel edges $\uparrow$ and o in $\mathcal{T}_{\mathrm{i}-1}$ share one node (closeness condition)).

A tree $\mathcal{T}=(\mathcal{H}, \mathcal{F})$ is an acyclic graph, which $\mathcal{H}$ is its set of nodes, and $\mathcal{F}$ is its set of edges. Acyclic means that there exists no direction such that it cycles. In a linked tree, we can reach each node from all other nodes in this tree. $\mathscr{R}$-vine is certainly a chain of related trees such that the edges of $\mathcal{T}_{\mathrm{i}}$ are the nodes of $\mathcal{T}_{\mathrm{i}+1}$. A conventional illustration of those structures is drawable vines (-vines) and canonical vines (-vines) (see Czado et al. (2010) and Aas et al. (2009)) in Fig. 1. A -vine is solely defined via its first tree, wherein each node has at most incoming edges, while every tree of a -vine is described by way of a root node, which has -1 incoming edges, in each tree $\mathcal{T}_{i}, i \in\{1, \ldots, m-1\}$.

Ordinary vines are an effective tool to systemize all feasible factorizations of a -dimensional density as a multiple of univariate marginal densities with a product of $(-1) / 2$ conditional and unconditional bivariate copulas (see Kurowicka and Cooke (2006), theorem 4.2). Thus, the unconditional and conditional bivariate copulas - called pair-copulas — of a given factorization can be uniquely
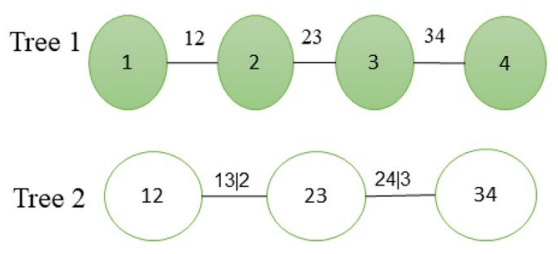

Tree 3

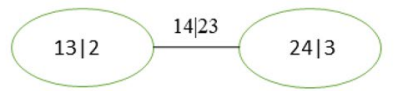

Tree 1

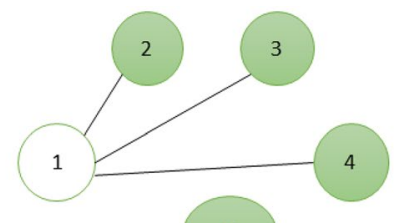

13

Tree 2

Tree 3
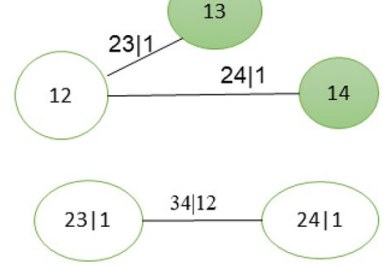

Fig. 1 Drawable-vine (on left) and canonical-vines (on right) representation for $\mathrm{n}=4$ 
mapped onto a set of edges $\mathcal{F}$ of a specific regular vine, and vice versa. Then, the conditional copulas and their arguments depend on the conditioned values. The dependence of conditional copulas on conditioned values is critical. It lets in for statistical packages manageable for a subclass of asymmetric distributions (see Stöber et al. (2013)) example conditioned pair copulas depend on conditioned values convenient thru their arguments. Aas et al. (2009) first developed this explanation further and went beyond the elliptical world. Accordingly, they have considered regular vine factorizations with arbitrary constant conditional copulas and confirmed that these effects in legitimate multivariate distributions and copulas. Here in this research, we also expect that conditional copulas rely on conditioned values the simplest through their arguments, and so that they may be chosen from bivariate copula families.

The range of regular vine structures with random variables can be massive. For $\leq 4$, only - and - and are viable. For $>4$, there are $\frac{\mathbb{1} !}{2}$ Unique - and -vines. The overall amount of ordinary vine systems has been computed by MoralesNápoles et al. (2010) and is identical to $\frac{\hat{1} !}{2} \cdot 2^{\left(\frac{m-2}{2}\right)}$. To pick conditional copulas on those graphical systems, we outline the subsequent sets of conditions outlined by Czado et al. (2010).

Definition 2 (Conditioned and conditioning sets) For any edge $e=\{\uparrow, o\} \in \mathcal{F}_{\mathrm{i}}$ of a regular vine $\mathrm{V}$, the complete union of $\mathrm{e}$ is the subset.

$$
\mathrm{B}_{\mathrm{e}}=\left\{\mathrm{v} \in \mathcal{H}_{1}: \forall \mathrm{m}=1, \ldots, \mathrm{i}-1, \exists \mathfrak{e}_{\mathrm{jm}} \in \mathcal{F}_{\mathrm{m}} \text { s.t.v } \in \mathfrak{e}_{\mathrm{j} 1} \in \ldots \ldots \in \mathfrak{e}_{\mathrm{ji}-1} \in \mathbf{e}\right\} .
$$

The conditioning set related to $\mathrm{e}$ is

$$
\mathrm{D}_{\mathrm{e}}=\mathrm{B}_{\uparrow} \cap \mathrm{B}_{\mathrm{o}}
$$

The conditioned sets related to $e$ are

$$
\begin{aligned}
& \mathrm{i}(\mathfrak{e})=\mathrm{B}_{\uparrow} \backslash \mathrm{D}_{\mathrm{e}} \\
& \mathrm{j}(\mathrm{e})=\mathrm{B}_{\mathrm{o}} \backslash \mathrm{D}_{\mathrm{e}}
\end{aligned}
$$

The copula for this edge will be represented by

$$
\mathrm{C}_{\mathrm{e}}:=\mathrm{C}_{\mathrm{i}(\mathrm{e}), \mathrm{j}(\mathrm{e}) \mid \mathrm{D}(\mathrm{e})} .
$$

Given a regular vine, we require a regular vine copula by allocating a (conditional) pair copula to every edge of the R-vine. For this, we observe the suggestion of Czado et al. (2012a, 2012b).

Definition 3 (Regular vine copula) A regular vine copula $\mathrm{C}=(\mathrm{V}, \mathcal{B}(\mathrm{V})),(\vartheta(\mathcal{B}(\mathrm{V}))$ in $\mathrm{m}$-dimensions are a multivariate distribution function such that for a random vector $\mathrm{W}=\left(\mathrm{W}_{1}, \ldots, \mathrm{W}_{\mathrm{m}}\right)^{\prime} \sim \mathrm{C}$ with uniform margins.

1. $\mathrm{V}$ is a regular vine with $n$ elements, 
2. $\mathcal{B}(\mathrm{V})=\left\{\mathrm{C}_{\mathrm{e}} \mid \mathrm{e} \in \mathcal{F}_{\mathrm{m}}, \mathrm{m}=1, \ldots \ldots, \mathrm{n}-1\right\}$ is a set of $\mathrm{m}(\mathrm{m}-1) / 2$ copula families classifying the unconditional distributions of $\mathrm{W}_{\mathrm{i}(\mathrm{e}) \mathrm{j}(\mathrm{e})}$ as well as the conditional distributions of $\mathrm{W}_{\mathrm{i}(e), j(e)} \mid \mathrm{W}_{\mathrm{D}(e)}$,

3. $\vartheta(\mathcal{B}(\mathrm{V}))=\left\{\vartheta_{\mathrm{e}} \mid \mathrm{e} \in \mathcal{F}_{\mathrm{m}}, \mathrm{m}=1, \ldots \ldots, \mathrm{n}-1\right\}$ is the set of parameter vectors conforming to the copulas in $\mathcal{B}(\mathrm{V})$.

To facilitate statistical inference, a matrix representation of $\mathscr{R}$-vines has become popular, proposed by Morales-Nápoles et al. (2010), further advanced by Dissmann et al. (2013). To specify an n-dimensional $\mathscr{R}$-vine in matrix form, one needs numerous lower triangular $n \times n$ matrices: one which stores the shape of the $\mathscr{R}$-vine, one with copula family, and the other two for parameter representation. n-dimensional $\mathscr{R}$-vine can be represented in matrix form as follows:

$$
\mathrm{Z}=\left(\begin{array}{ccc}
\mathrm{z}_{1,1} & \cdots & \mathrm{z}_{1, \mathrm{n}} \\
\vdots & \ddots & \vdots \\
\mathrm{z}_{\mathrm{n}, 1} & \cdots & \mathrm{z}_{\mathrm{n}, \mathrm{n}}
\end{array}\right),
$$

where $z_{i, j} \epsilon(1, \ldots, n)$. The guidelines for understanding this matrix are as follows. The conditioned set for an entry $z_{\mathrm{j}, \mathrm{j}}$ are the entree itself and the diagonal entree of the column $\mathrm{z}_{\mathrm{j}, \mathrm{j}}$ whereas the conditioning set is composed of variables underneath the entree; i.e., for $\mathrm{z}_{\mathrm{j}, \mathrm{j}}$, the conditioned set will be $\left(\mathrm{z}_{\mathrm{i}, \mathrm{j}}, \mathrm{z}_{\mathrm{j}, \mathrm{j}}\right)$, the conditioning set is $\left(z_{i+1, j}, z_{n, j}\right)$.Thus, $z_{i, j}$ denotes the node $\left(z_{i, j}, z_{j, j} \mid z_{i+1, j}, \ldots \ldots \ldots, z_{n, j}\right)$. We will count on that the diagonal of $\mathrm{Z}$ is sorted in descending order, which could always be completed by way of reordering the node labels so that we've $z_{j, j}=n-i+1$. To illustrate the $\mathscr{R}$-vine matrix notation, we consider the -vine from Fig. 1 and give beneath its $\mathscr{R}$-vine matrix representation.

$$
\left(\begin{array}{llll}
4 & * & * & * \\
3 & 3 & * & * \\
2 & 2 & 2 & * \\
1 & 1 & 1 & 1
\end{array}\right)
$$

The Opening column encodes the following nodes.

1. Knob 43 $\mid 21$ is kept over $z_{1,1}, z_{2,1}$, given $z_{3,1}$, and $z_{4,1}$;

2. Knob $42 \mid 1$ is kept over $z_{1,1}, z_{3,1}$, given $z_{4,1}$;

3. Knob 41 is kept over $z_{1,1}, z_{4,1}$.

In the development, we use -vines to capture the cross-sectional reliance of more than one series at any time point $t$. For achieving the reliance between multivariate observations, the initial tree of the -vine for multivariate observation at time factor $t$ is connected to the first tree of the -vines for present neighboring multivariate observations at time factors $t-1$ and $t+1$ with one aspect, correspondingly. This outcome in the first tree of an $\mathscr{R}$-vine for all multivariate observations handled as one large sample point. Relying on the choice of -vines and the relationship of the primary trees, the autoregressive copula version of Brechmann and Czado (2015) in the coming segment can be acquired. 


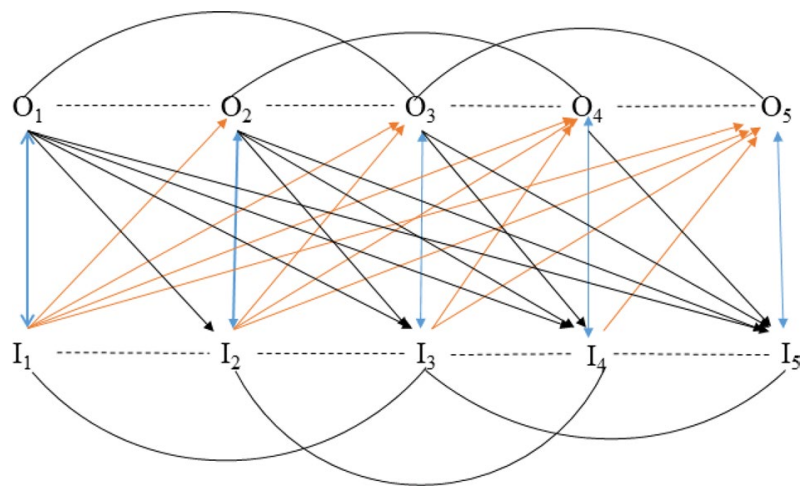

Fig. 2 Simulation dependent structure of bivariate time series for $\mathrm{N}=5$. Horizontal dotted and lines characterize: serial reliance for each time series; vertical blue two sided arrows represent; cross-sectional dependence; black and orange arrows: cross-serial reliance

Finally, note that the copula families and their parameters are further saved in lower triangular $n \times n$ matrices. Every element of the $\mathscr{R}$-vine matrix below the diagonal specifies a conditional or unconditional pair copula depending on the diagonal entry above it. This pair copula's own family and parameters are now entered in the same access locality of matrices for copula families and parameters. As the diagonal entries of the $\mathscr{R}$-vine matrix alone do not define any pair copulas, no listings for the copula family and parameter matrices are required. For simplicity purposes, the main diagonal is filled with the aid of *sign.

\section{Implementation of Vine Copulas in Autoregressive Model}

$\mathscr{R}$-vines have been the foremost used to model contemporaneous dependence. We now present a special $\mathscr{R}$-vine shape called copula autoregressive model from Brechmann and Czado (2015), which is intended to capture all three (serial, cross-serial) reliances in multivariate time collection at a time, and let in general Markovian Structure. Assume that $\left\{\mathrm{O}_{\mathrm{t}}, \mathrm{I}_{\mathrm{t}}\right\}_{\mathrm{t}=1,2, \ldots, \mathrm{N}}$ be an observable two stationary time series. To demonstrate how the two time series are mutually dependent, do not forget the mapping of dependencies for $\mathrm{N}=5$ in Fig. 2. Vertical blue two-sided arrows represent the cross-sectional reliance. Horizontal dotted and curved lines represent the serial dependence for each time series, and vertical black and orange arrows represent the cross-serial dependency.

Horizontal dotted and lines characterized: serial reliance for each time series; vertical blue two-sided arrows represent: cross-sectional dependence; black and orange arrows: cross-serial reliance.

Historically $\mathscr{R}$-vines had been used for the simplest cross-sectional reliance (which is denoted through the vertical blue two-sided arrows in Fig. 2), but underneath the idea that different dependencies are absent under the assumption that the data is identically independently distributed. The copula autoregressive 
demonstration is intended to seize sequential and cross-serial reliance additionally. The subsequent explanation of a COPAR (Copula autoregressive model) with Markovian shape for two series following by our representation is occupied by Brechmann and Czado (2015). The vectors $\left(\mathrm{O}_{\mathrm{r}}, \ldots, \mathrm{O}_{\mathrm{t}}\right)$ and $\left(\mathrm{I}_{\mathrm{r}}, \ldots, \mathrm{I}_{\mathrm{t}}\right)$ are denoted as $\mathbf{O}_{\mathrm{r}: \mathrm{t}}$ and $\mathbf{I}_{\mathrm{r}: \mathrm{t}}$, separately.

Definition 4 COPAR model (Two variable cases) The COPAR model for stationary continuous time series $\left\{\mathrm{O}_{\mathrm{t}}\right\}_{\mathrm{t}=1,2, \ldots, \mathrm{N}}$ and $\left\{\mathrm{I}_{\mathrm{t}}\right\}_{\mathrm{t}=1,2, \ldots, \mathrm{N}}$ has the subsequent modules.

(a) Unconditional marginal distributions of all time series are independent of time.

(b) An $\mathscr{R}$-vine for the serial and between-series reliance of $\left\{\mathrm{O}_{\mathrm{t}}\right\}_{\mathrm{t}=1,2, \ldots, \mathrm{N}}$ and $\left\{\mathrm{I}_{\mathrm{t}}\right\}_{\mathrm{t}=1,2, \ldots, \mathrm{N}^{*}}$

The subsequent pairs are carefully chosen.

1. Sequential reliance on $\left\{\mathrm{O}_{\mathrm{t}}\right\}_{\mathrm{t}=1,2, \ldots, \mathrm{N}}$ : The pairs of serial D-vine copula for $\mathrm{O}_{1}, \ldots \ldots \mathrm{O}_{\mathrm{N}}$; that is,

$$
\mathrm{O}_{\mathrm{r}}, \mathrm{O}_{\mathrm{t}} \mid \mathrm{O}_{(\mathrm{r}+1):(\mathrm{t}-1)}, 1 \leq \mathrm{r}<\mathrm{t} \leq \mathrm{N} .
$$

2. Between-series reliance:

$$
\mathrm{O}_{\mathrm{r}}, \mathrm{I}_{\mathrm{t}} \mid \mathrm{O}_{(\mathrm{r}+1): \mathrm{t}}, 1 \leq \mathrm{r}<\mathrm{t} \leq \mathrm{N} .
$$

and

$$
\mathrm{I}_{\mathrm{r}}, \mathrm{O}_{\mathrm{t}} \mid \mathrm{O}_{1:(\mathrm{t}-1)}, \mathrm{I}_{(\mathrm{r}+1):(\mathrm{t}-1)}, 1 \leq \mathrm{r}<\mathrm{t} \leq \mathrm{N} .
$$

3. Conditional sequential reliance on $\left\{I_{t}\right\}_{t=1,2, \ldots, N}$ : The pairs of a sequential -vine copula for $1, \ldots, I_{N}$ conditioned on all previous values of $\left\{\mathrm{O}_{\mathrm{t}}\right\}_{\mathrm{t}=1,2, \ldots, \mathrm{N}}$; that is,

$$
\mathrm{I}_{\mathrm{r}}, \mathrm{I}_{\mathrm{t}} \mid \mathrm{O}_{1: \mathrm{t}}, \mathrm{I}_{(\mathrm{r}+1):(\mathrm{t}-1)}, 1 \leq \mathrm{r}<\mathrm{t} \leq \mathrm{N} \text {. }
$$

Pair copulas of the same lag length $t-r, t \geq r$, are indistinguishable. We associate.

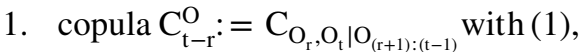

2. copulas $\mathrm{C}_{\mathrm{t}-\mathrm{r}}^{\mathrm{O} \mathrm{I}}:=\mathrm{C}_{\mathrm{O}_{\mathrm{r}}, \mathrm{I}_{\mathrm{t}} \mid \mathrm{O}_{(\mathrm{r}+1): t}}$ and $\mathrm{C}_{\mathrm{t}-\mathrm{r}}^{\mathrm{I} . \mathrm{O}}=\mathrm{C}_{\mathrm{I}_{\mathrm{r}}, \mathrm{O}_{\mathrm{t}} \mid \mathrm{O}_{1:(t-1),} \mathrm{I}_{(\mathrm{r}+1):(t-1)}}$ with(2) and (3), individually, and

3. copula $C_{t-r}^{I}:=C_{I_{r}, I_{t} \mid O_{1:(t-1),(r+1):(t-1)}}$ with (4) individually.

The explanation of the above definition on an example of a two series $\left\{\mathrm{O}_{\mathrm{t}}, \mathrm{I}_{\mathrm{t}}\right\}_{\mathrm{t}=1,2, \ldots .5}$ with five observations are as follows. Using a -vine, Eq. 1 captures the reliance structure of $\mathrm{O}_{1}, \mathrm{O}_{2}, \mathrm{O}_{3}, \mathrm{O}_{4}$ and $\mathrm{O}_{5}$ expressed employing the top lines connecting them in Fig. 2 for $r=1$ and $t=5$, Eq. 2 portrays the contingent dependence among $\mathrm{O}_{1}$ and $\mathrm{I}_{5}$ conditioned on $\mathrm{O}_{2}, \mathrm{O}_{3}, \mathrm{O}_{4}$ and $\mathrm{O}_{5}$. Accordingly, Eq. 2 
captures the conditional reliance between $\mathrm{O}_{\mathrm{r}}$ and $\mathrm{I}_{\mathrm{t}}$ for $\mathrm{r}<\mathrm{t}$ meditated by way of the black arrows in Fig. 2 for $\mathrm{r}=\mathrm{t}$, Eq. 2 models the unconditional reliance among $O_{t}$ and $I_{t}$ expressed by way of the double-sided blue arrows. Besides, Eq. 3 depicts the restrictive sequential dependence among individual time collections illustrated with the aid of the orange arrows in Fig. 2, but Eqns. 2-3 are not symmetric with appreciation to conditioned units. Especially, the conditional distribution of $O_{r}$ and $I_{t}$ for $\mathrm{r}<\mathrm{t}$ is impartial of $\mathrm{I}_{1}, \ldots, \mathrm{I}_{\mathrm{t}-1}$. It is of now demonstrates that the first run through an arrangement $\left\{O_{t}, I_{t}\right\}_{t=1,2, \ldots, N}$ plays a key job inside the stochastic elements of the time-varying observations, considering its far adequate to portray the restrictive dependence among $O_{r}$ and $I_{t}$ for $\mathrm{r}<\mathrm{t}$. Therefore, the individual time series aren't exchangeable. The use of a -vine, Eq. 4 sooner or later describes the reliance structure of $\mathrm{I}_{1}, \ldots, \mathrm{I}_{\mathrm{N}}$ (represented by dotted lines between the second series in Fig. 2) conditioned on $\mathrm{O}_{1}, \mathrm{O}_{2}, \ldots, \mathrm{O}_{\mathrm{N}}$ because the effects of copulas of the similar slack extension are the same, the COPAR model characterizes a fixed bivariate event arrangement.

As illustrated by Brechmann and Czado (2015) and further implemented by Ivanov et al. (2017) in his work, the bivariate copula autoregressive model can be extended to multivariate time series with Markov structure by considering $p$ time series observed at $\mathrm{N}$ time points; that is, $\left\{O_{1, t}, \ldots, O_{p, t}\right\}_{t=1, \ldots, N}$.

Let us consider a vector of $p$ univariate time series perceived at time $t=1, \ldots$, $\mathrm{N}$

$$
O_{t}=\left(O_{1, t}, \ldots, O_{p, t}\right)^{\prime}
$$

Where $i=1,2, \ldots, p$ representing individual series observed at time $\mathrm{t}=1, \ldots, \mathrm{N}$, i.e.

$O^{(i)}=\left(O_{i, 1}, \ldots, O_{i, N}\right)$, also consider a vector $O_{l: p, r: t}=\left(O_{1, r}, \ldots, O_{l, t} \ldots, O_{p, r}, \ldots, O_{p, t}\right)$ for understanding purposes. Then the autoregressive copula model for multiple time series of order $\mathrm{k}$ for our notation can be defined as:

Definition 5 COPAR model of order $k$ (for p-time series with $N$ time points) The $\operatorname{COPAR}(\kappa)$ model for a p dimensional stationary time series $O_{t} \epsilon \mathcal{R}^{p \times 1}, t=1,2, \ldots, N$ has the resulting mechanisms.

(a) Unconditional marginal distributions of all time series are independent of time.

(b) An $\mathscr{R}$-vine for the serial and between-series reliance of $O_{t} \epsilon \mathcal{R}^{p \times 1}, t=1,2, \ldots, N$,

where the subsequent pairs are carefully chosen.

1. Serial reliance on $O^{(1)}$ : The pairs of serial -vine copula for $O_{1,1}, \ldots, O_{1, N}$; that is,

$$
O_{1, r}, O_{1, t} \mid O_{1,(r+1):(t-1)}, 1 \leq r<t \leq N .
$$

2. Between-series reliance of $O^{(i)}$ and $O^{(j)}$ for $\mathrm{i}<\mathrm{j}, \mathrm{i}, \mathrm{j}=1, \ldots, \mathrm{p}$ :

$$
O_{i, r}, O_{j, t} \mid O_{1:(i-1), 1: t}, O_{i:(r+1): t} 1 \leq r<t \leq N,
$$


and

$$
O_{i, s}, O_{j, t} \mid O_{1:(i-1), 1: t}, O_{i:(j-1), 1:(t-1)}, O_{i:(r+1):(t-1)} 1 \leq r<t \leq N,
$$

3. Conditional serial reliance of $O^{(1)}$ for $2 \leq i \leq p$ :

$$
O_{i, r}, O_{j, t} \mid O_{1:(i-1), 1: t}, O_{i:(r+1):(t-1)} 1 \leq r<t \leq N,
$$

whereas.

(i) copulas $\forall i$ and for lag length $t-r>k$ are independent copulas,

(ii) copulas for $i, j=1,2, \ldots . ., p$ for the same lag length $t-r, t \geq r$ are indistinguishable.

Definition 5 presents a multivariate copula autoregressive model, with the chance that $\mathrm{I}$ ) is ignored. The confidence of $O^{(i)}$ is showed adapted on $O^{(1)}, \ldots, O^{(i-1)}$, and in this manner, the request for factors cannot be, without doubt, interchanged. The pair copulas in the autoregressive copula model of order $\mathrm{k}$ for time arrangement with Markovian structure are independent of time, and the number of sets is not exactly the number allured for a standard customary vine. To acknowledge to the scope of pair copulas, the ensuing outcome of Brechmann and Czado (2015) holds.

Lemma 1 The range of copulas required for a COPAR $(k)$ model of $p$ univariate time series is $p^{2} k+\frac{p(p-1)}{2}$.

It is to be noticed that the number of parameters in a vector autoregressive model of order $\mathrm{k}$ for the cross-sectional dependence of $p$ time series-without parameters for marginal-is the same as for pair copulas in a copula autoregressive model of the same order. That is why the scope of parameters in a COPAR-model is jumped through two or three times the number of VAR parameters given the number of parameters of the included copula families. Conversely, a common regular vine copula requires $\frac{p N(p N-1)}{2}$ pair-copulas, bringing about a large number of parameters.

\section{Granger Causality}

The above-stated copula autoregressive model is beneficial only when one series Granger reasons. One time-varying variable plays an essential role, and for a reason, that univariate time series are not interchangeable. Consequently, it is vital to investigate Granger causality among time series before implementing COPAR-model.

Granger causality means one time series $\left\{O_{t}\right\} t=1,2, \ldots \ldots, N$ provides significant information about $\left\{I_{t}\right\}$; which is helpful in prediction of $\left\{I_{t}\right\}$ from $\left\{O_{t}\right\}$. Granger causality is frequently represented as $\left\{O_{t}\right\} \rightarrow\left\{I_{t}\right\}$ ( $\left\{O_{t}\right\}$ Granger causes $\left\{I_{t}\right\}$ ). Further, $\left\{O_{t}\right\} t=1,2, \ldots, N$ does not Granger cause $\left\{I_{t}\right\} t=1,2, \ldots, N$ if $\left\{O_{t}\right\}$ does not have any clarifying power concerning upcoming observations $I_{N+r} r \geq 1$. 
As outlined by Brechmann and Czado (2015) in their work, Granger causality can be investigated through the COPAR model. The conditional distribution of $I_{N+s \mid I_{1: N}}$, $O_{1: N}$ are directly obtained from COPAR. According to COPAR if $\left\{O_{t}\right\}$ Granger cause $\left\{I_{t}\right\}$, then this distribution is not equal to that of $I_{N+s \mid I_{1: N}}$, which means that all the pairs of $\left\{I_{t}\right\}$ and $\left\{O_{t}\right\}$, specifying between-series dependence is independent. In that case, the model will be reduced to two independent -vine serial copulas for $\left\{I_{t}\right\}$ and $\left\{O_{t}\right\}$, respectively. The two independent models are nested when the pair copulas of the sequential -vine are chosen assets in the full model. Let us assume that the log probability of the consolidated model of $\left\{I_{t}\right\}$ and $\left\{O_{t}\right\}$ be indicated by $\uparrow_{\mathcal{R} V}$ and the equivalent of the aggregate one of the two separate -vine copulas for $\left\{I_{t}\right\}$ and $\left\{O_{t}\right\}$ are $\uparrow_{\mathcal{D} V}$ worked with the indistinguishable pair copulas because of the joint variant; at that point, the proportion $2\left(\uparrow_{\mathcal{R} V}-\uparrow_{\mathcal{D} V}\right)$ follows $\chi^{2}$ distribution with $P_{\mathcal{R} V}-P_{\mathcal{D} V}$ degrees of freedom, where $P_{\mathcal{R} V}$ and $P_{\mathcal{D} V}$ are the parametrization of the two models (full and reduced) individually. For various copula families, the test proposed by Vuong (1989) is suggested for nonsettled theories. Tolerating the speculation that the between-observation reliance is not critical implies that there is no Granger causality. For additional subtleties, see Brechmann and Czado (2015).

\section{Empirical Results and Discussion}

\section{Data Information}

The data used in this analysis are obtained from the State Bank of Pakistan (SBP) and Pakistan Bureau of information (PBS) and cover 147 monthly observations from January 2008 to April 2020 of the following four month-to-month Pak macrofinancial variables: continuously compounded gasoline price (G.P.) USD/liter in Pakistan, the real interest rate of 30-day notified by SBP in Pak (I.R.), inflation rate (IF) and industrial production (I.P.) of Pakistan. All results reported in this investigation are carried out in the R-studio environment through VineCopula package version 2.3.0.

The underline time series are presented in Fig. 3. The observed rank associations (for serial reliance without correction) of gasoline price inside the country with other time series are positive: 0.17477 for the inflation rate, 0.20723 for interest rates, and 0.21745 for commercial production. In the subsequent, we can inspect the behaviors
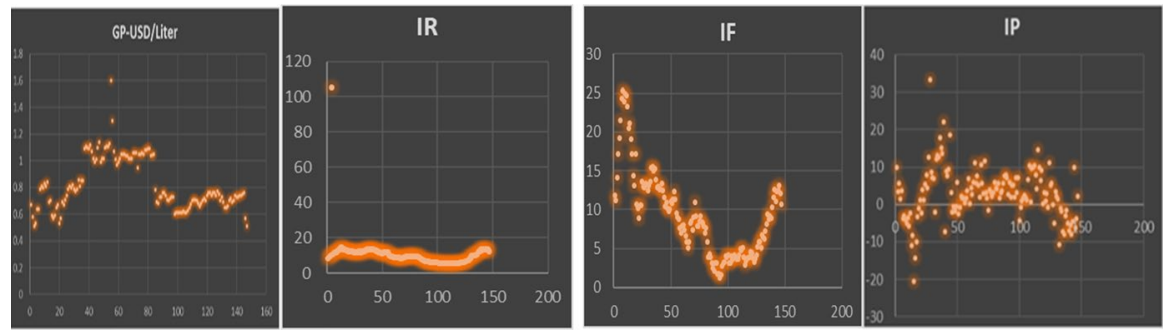

Fig. 3 History plot of macroeconomic and financial variables in the country 


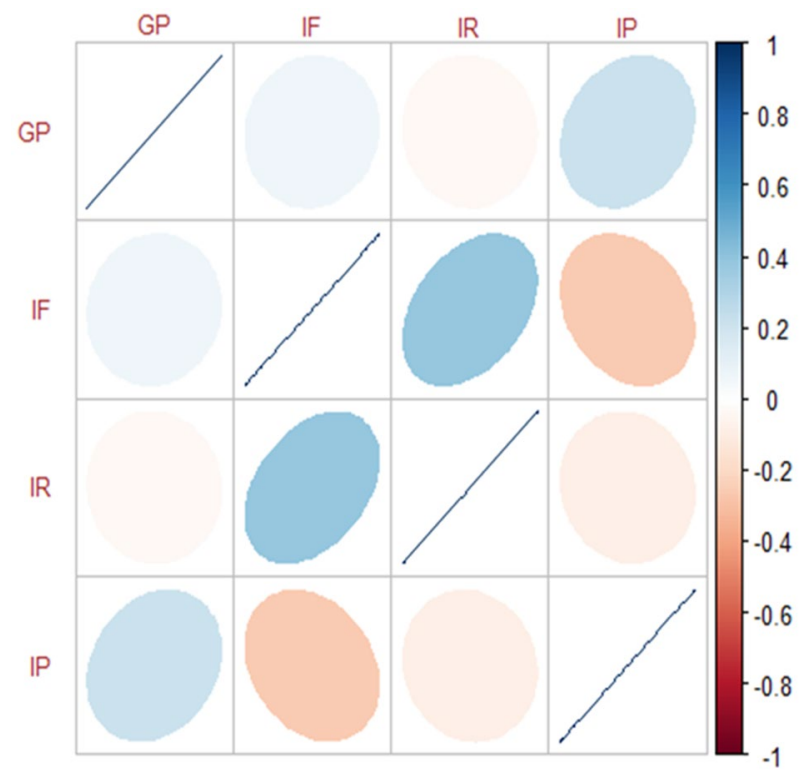

Fig. 4 Observed Correlation of Gasoline price with other indicators

Table 1 Marginal distribution parameter estimation

\begin{tabular}{lrll}
\hline Indicator & \multicolumn{2}{l}{ Skew-normal } & \\
\cline { 2 - 4 } & Location & Scale & Skew \\
\hline GP & 0.5890 & 0.3008 & 0.8453 \\
IF & 2.2646 & 8.8251 & 0.9565 \\
IR & 5.5265 & 9.5847 & 0.9948 \\
IP & -1.4190 & 8.1531 & 0.1144 \\
\hline
\end{tabular}

of those dependencies and examine whether the oil price has good sized illustrative power with respect to the contrasting three macroeconomic indicators. The observed rank correlation among time series is presented graphically in matrix form in Fig. 4.

\section{Advanced Analysis}

Within the first step, to investigate the skewness and heavy tailness of the variables, that is a common phenomenon of much financial time series, the skew-normal distributions for each of the four time series were fitted with the help of Azzalini (1985) parameterizations, where the location parameter represents the skewness. If the location is equal to zero, there is no skewness, and the underline appropriation will be normal. Graphs of each of those variables are given in Appendix 3, whereas the corresponding estimated parameters are presented in Table 1. They imply that the observed time series are not normal and heavy-tailed. 
Next, before we proceed further, we inspect Granger causality among the time series. The Granger causality summary is supplied under Table 4; Appendix 3. Its observed that the gasoline price Granger causes an inflation rate at a $10 \%$ level of significance. Allowing the COPAR model with skewed margins, the p-value supposes that the gasoline price does not Granger cause an inflation rate still equal to 0.027. One might not powerfully discard the null supposition. This is due to the small observed association of 0.174 determined between the two series. Whereas gasoline prices significantly Granger cause interest rates and industrial production at $1 \%$ significance levels.

We formerly built an appropriate two-variable COPAR-model for interest rate, inflation, and industrial manufacturing (by way of crucial indicators) with recognition of oil price to investigate oil rate consequences. The appropriate lag length of the models is chosen with Akaike, Bayesian, and Hannan-Quinn information criteria. Figure 5a-c indicates HQC, BIC, and AIC of COPAR-model for k=1,.., 4. Furthermore, we fixed the family of all pair copulas as Gaussian copula to make the estimation simple. Gaussian copula can utilize only one parameter and model both negative and positive dependence; therefore, we use Gaussian pair copula as a proxy for lag length selection. The plots represent the correct autoregressive order of one (that is, $k=1$ ).

The sequential copula selection and likelihood calculation are not straightforward in the COPAR. For likelihood computation, of course, the R-vine structure matrix specification could be used instead. However, given that the number of time points $T$ might be large, evaluating this $2 T$-by- $2 T$ matrix is computationally rather inefficient. Most matrix entries do not contain any information due to the assumed autoregressive order. For simplicity of computation for sequential copula selection, we follow the following steps:

The joint density of $\boldsymbol{X}=\left(X_{1}, X_{2}, \ldots, X_{d}\right)^{\prime}$ distributed according to an R-vine paircopula decomposition is uniquely determined and given by

$$
f_{1: d}\left(x_{1}, \ldots, x_{d}\right)=\prod_{k=1}^{d} f_{k}\left(x_{k}\right) \prod_{i=1}^{d=1} \prod_{e \epsilon \varepsilon_{i}} c_{j(e), k(e) \mid D(e)}\left(F_{j(e) \mid D(e)}\left(x_{j(e)} \mid x_{D(e)}\right), F_{k(e) \mid D(e)}\left(x_{k(e)} \mid x_{D(e)}\right)\right)
$$

where $x_{D(e)}$ denotes the sub-vector of $\boldsymbol{x}=\left(x_{1}, \ldots, x_{d}\right)^{\prime}$ determine by the indices in $\mathrm{D}(\mathrm{e})$. Typically, it is assumed that copulas $c_{j(e), k(e) \mid D(e)}$ only depend on the conditioning values $x_{D(e)}$. The arguments of copulas in tree $T_{i}$ can be recursively computed from copulas in trees $T_{1}, \ldots . T_{i-1}$ using the general formula given below:

$$
F_{X \mid V}(x \mid v)=\frac{\partial C_{X, V_{j} \mid V_{-j}}\left(F_{X \mid V_{-j}}\left(x \mid v_{-j}\right), F_{V_{j} \mid V_{-j}}\left(v_{j} \mid v_{-j}\right)\right)}{\partial F_{V_{j} \mid V_{-j}}\left(v_{j} \mid v_{-j}\right)}
$$

where $C_{X, V_{j} \mid V_{-j}}$ is the bivariate copula of $X$ and $V j$ given $V-j$, where $V j$ is an arbitrary component of $V$ and $V-j$ denotes the vector $V$ excluding $V j$.

(i) Serial dependence of $\left\{\mathrm{O}_{\mathrm{t}}\right\}_{\mathrm{t}=1,2, \ldots, N}: \mathrm{O}_{\mathrm{r}}, \mathrm{O}_{\mathrm{t}} \mid \mathrm{O}_{r+1} \ldots, \mathrm{O}_{t-1} 1 \leq \mathrm{s}<\mathrm{t} \leq \mathrm{T}$.

(ii) Select Copula $C_{1}^{X}=C_{X_{t-1}, X_{t}}$ based on 


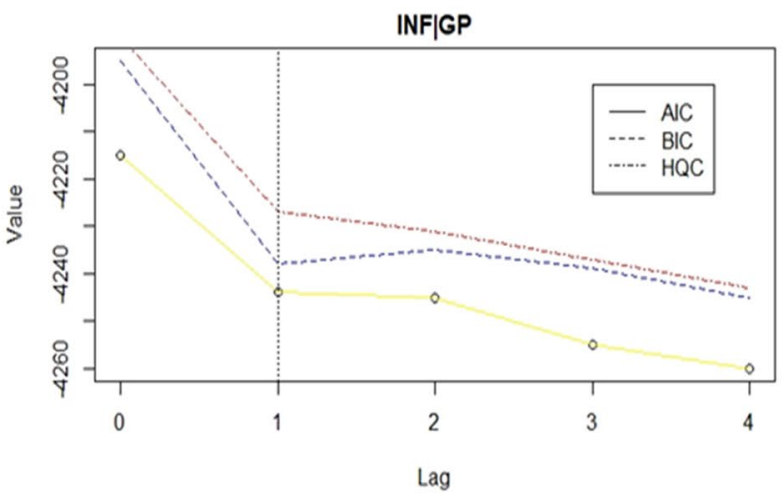

a Leg length selection for inflation and oil price copula model

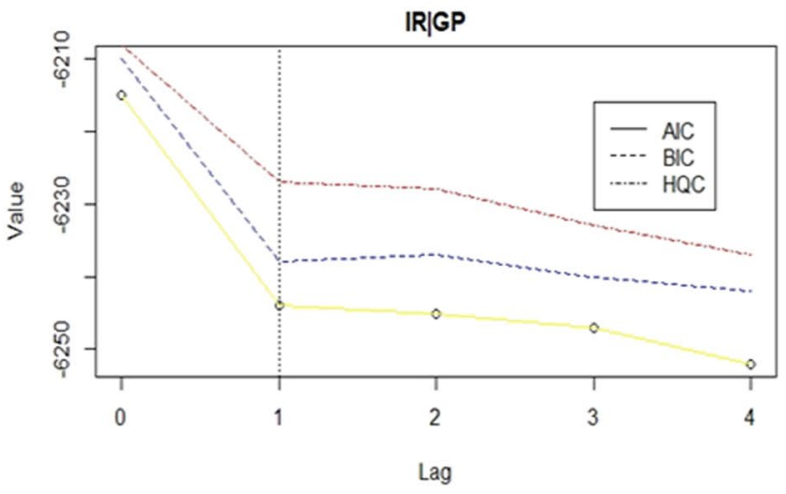

b Leg length selection for interest rate and oil price copula model

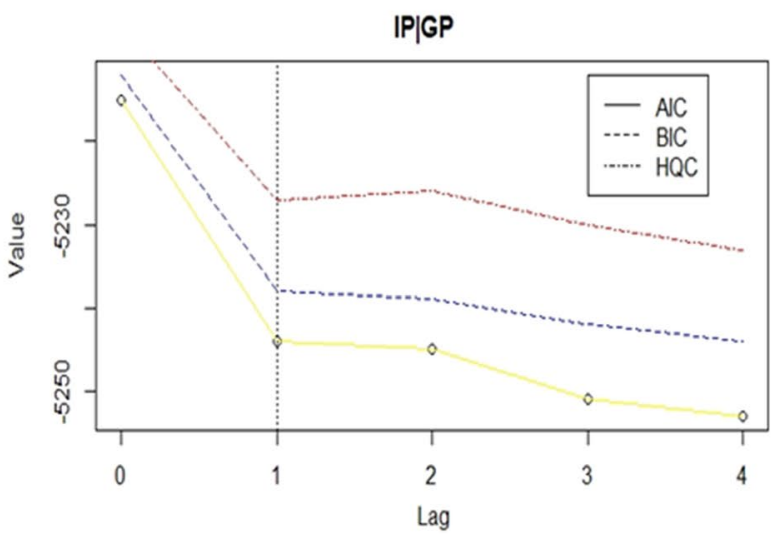

c Leg length selection among industrial production and oil price copula models

Fig. 5 a-c Lag length selection for COPAR model using information criteria 


$$
\mathrm{F}_{\mathrm{X},}\left(\mathrm{x}_{\mathrm{t}}\right)_{\mathrm{t}=2, \ldots, \mathrm{T}-1} \text { and } \mathrm{F}_{\mathrm{X},}\left(\mathrm{x}_{\mathrm{t}}\right)_{\mathrm{t}=2, \ldots, \mathrm{T}}
$$

(iii) Compute $F_{X_{t} \mid X_{t-1}}\left(x_{t} \mid x_{t-1}\right), t=3 \ldots, T$, and $F_{X_{t-1} \mid X_{t}}\left(x_{t-1} \mid x_{t}\right), t=2,3 \ldots, T$, from $C_{1}^{X}$ using above expression (A).

(iv) Between-series dependence $X_{s}, X_{t} \mid X_{s+1}, \ldots, X_{t}, 1 \leq \mathrm{s}<\mathrm{t} \leq \mathrm{T}$

(a) Select copula $\mathrm{C}_{0}^{\mathrm{XY}}=\mathrm{C}_{\mathrm{X}_{\mathrm{t}}, \mathrm{Y}_{\mathrm{t}}}$ based on $\{F x(x t)\}_{t=1,2, \ldots, T}$ and $\{F y(y t)\}_{t=1,2, \ldots, T}$

(b) Compute $F_{Y_{t} \mid X_{t}}\left(y_{t} \mid x_{t}\right), t=2 \ldots, T$, from $\mathrm{C}_{0}^{\mathrm{XY}}$ using expression (A) above.

(c) Select $\mathrm{C}_{1}^{\mathrm{XY}}=\mathrm{C}_{\mathrm{X}_{\mathrm{t}-1}, \mathrm{Y}_{\mathrm{t}} \mid \mathrm{X}_{\mathrm{t}}}$ based on $F_{X_{t-1} \mid X_{t}}\left(x_{t-1} \mid x_{t}\right), t=2 \ldots, T$ and $F_{Y_{t} \mid X_{t}}\left(y_{t} \mid x_{t}\right), t=2 \ldots, T$.

(d) Compute $F_{Y_{t} \mid X_{(t-): t}}\left(y_{t} \mid x_{t-1}, x_{t}\right), t=3, \ldots, T$, from $\mathrm{C}_{1}^{\mathrm{XY}}$ using expression (A) above

(v) Between-series dependence $Y_{s}, X_{t} \mid X_{1}, \ldots, X_{t-1}, Y_{s+1}, \ldots, Y_{t-1}, 1 \leq \mathrm{s}<\mathrm{t} \leq \mathrm{T}$ and conditional serial dependence of

$$
\left\{Y_{t}\right\}_{t=1,2, \ldots, T}: Y_{s}, Y_{t} \mid X_{1}, \ldots, X_{t}, Y_{s+1}, \ldots, Y_{t-1}, 1 \leq \mathrm{s}<\mathrm{t} \leq \mathrm{T}
$$

(vi) S e le c t copula $\quad \mathrm{C}_{1}^{\mathrm{YX}}=\mathrm{C}_{\mathrm{Y}_{\mathrm{t}-1}, \mathrm{X}_{\mathrm{t}} \mid \mathrm{X}_{1:(\mathrm{t}-1)}}$

$F_{Y_{t} \mid X_{1: t}}\left(y_{t} \mid x_{1}, \ldots, x_{t}\right), t=1, \ldots, T-1$

$F_{X_{t} \mid X_{1:(t-1)}}\left(x_{t} \mid x_{1}, \ldots, x_{t-1}\right), t=2, \ldots, T$,

where

$$
F_{Y_{t} \mid X_{1: t}}\left(y_{t} \mid x_{1}, \ldots, x_{t}\right)=F_{Y_{t} \mid X_{(t-2): t}}\left(y_{t} \mid x_{t-2}, x_{t-1,} x_{t}\right), \mathrm{t} \geq 3
$$

And

$$
F_{X_{t} \mid X_{1:(t-1)}}\left(x_{t} \mid x_{1}, \ldots, x_{t-1}\right)=F_{X_{t} \mid X_{(t-2):(t-1)}}\left(x_{t} \mid x_{t-2}, x_{t-1,}\right), \mathrm{t} \geq 3
$$

(vii) Compute $\quad F_{X_{t} \mid X_{1:(t-1)}, Y_{t-1}}\left(x_{t} \mid x_{1}, \ldots, x_{t-1}, y_{t-1}\right), \quad \mathrm{t}=3, \ldots, \mathrm{T} \quad$ and $F_{Y_{t}-1 \mid X_{1: t}}\left(y_{t-1} \mid x_{1}, \ldots, x_{t}\right), \mathrm{t}=2, \ldots, \mathrm{T}$ from $\mathrm{C}_{1}^{\mathrm{XY}}$ using expression (A) above

(viii) Select copula $\mathrm{C}_{1}^{\mathrm{Y}}=\mathrm{C}_{\mathrm{Y}_{\mathrm{t}-1}, \mathrm{Y}_{\mathrm{t}} \mid \mathrm{X}_{1: \mathrm{t}}}$ based on $F_{Y_{t}-1 \mid X_{1: t}}\left(y_{t-1} \mid x_{1}, \ldots, x_{t}\right), \mathrm{t}=2, \ldots, \mathrm{T}$ and

$$
\begin{aligned}
& F_{Y_{t} \mid X_{1: t}}\left(y_{t} \mid x_{1}, \ldots, x_{t}\right), \mathrm{t}=2, \ldots, \mathrm{T} \\
& \text { where } \\
& F_{Y_{t}-1 \mid X_{1: t}}\left(y_{t-1} \mid x_{1}, \ldots, x_{t}\right)=F_{Y_{t}-1 \mid X_{(t-3): t}}\left(y_{t-1} \mid x_{t-3}, \ldots, x_{t}\right), \mathrm{t} \geq 4
\end{aligned}
$$

The steps used for sequential copula selection in the autoregressive copula model can be graphically presented in Fig. 6.

Accordingly, COPAR (1) models are operational on the observed time series as defined in the methodology section, where copulas are decided based on AIC and BIC from a variety of altered families catching numerous types of reliance (lower-tail-dependence employing Clayton Copula, tail-dependence through Student's t copula, tail-symmetric and tail independent and tail-symmetric by Frank 


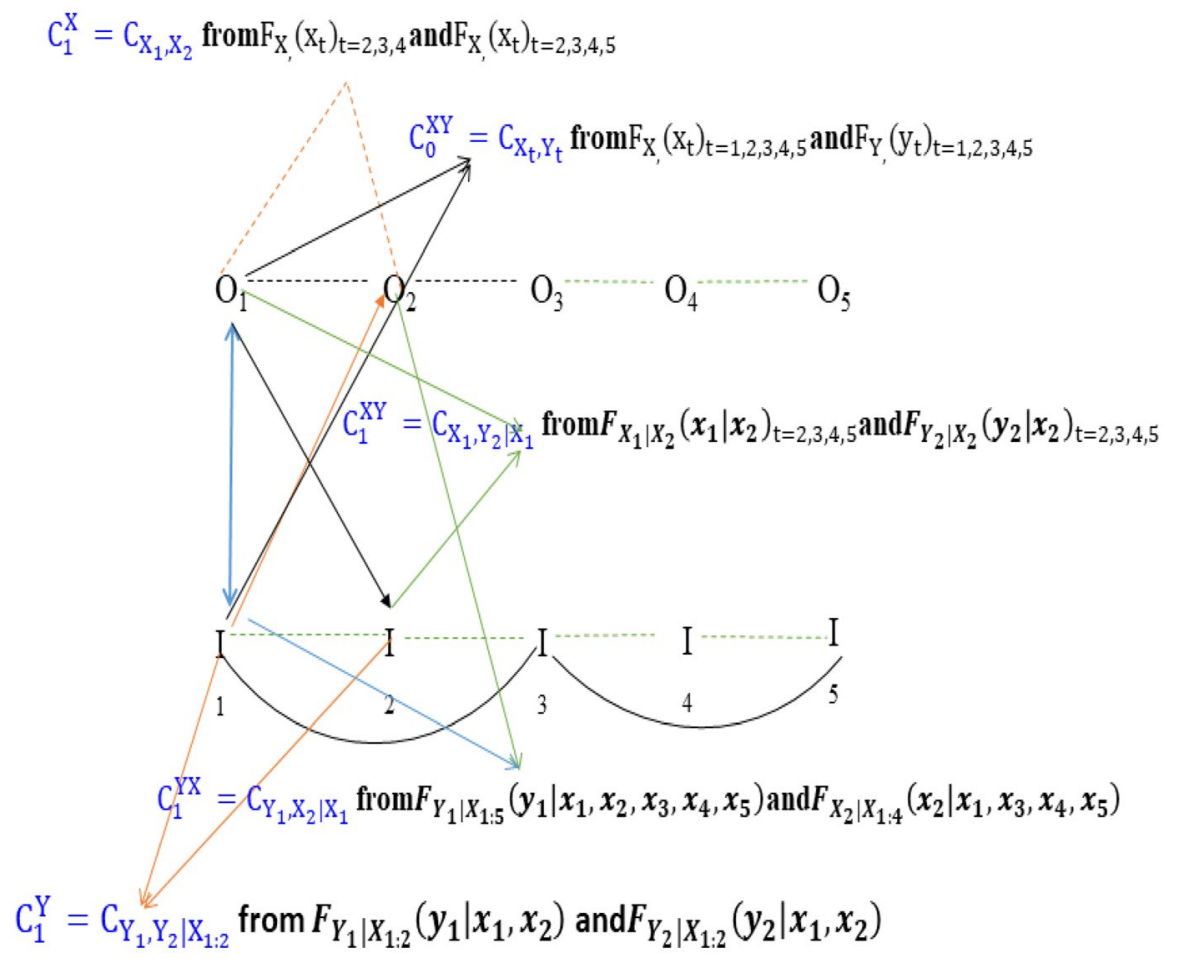

Fig. 6 Graphical presentation of sequential copula selection

copula and Gaussian copula, upper-tail-dependence by Gumbel Copula, Tawn copula, Joe copula and their upgraded version (Rotated Tawn type 1, Survival copula etc.). The parameters of these copulas are smooth to understand because of their relationships with Kendall's $\tau$. The degree of freedom indicates the strength of tail reliance inside Student's t copula's situation: the greater the freedom level, the weaker the tail reliance. More tractability regarding the tails may be acquired by using Joe-Clayton copulas, as Patton (2006) did in his work. However, such copulas are very complicated in specifying and interpreting. Here, the chosen copulas and their parameters were estimated through the maximum likelihood method of estimation (MLE) and are presented in Table 2 (for copula families and their order as per the VineCopula package, see Table 5; Appendix 3). The improved interdependence among variables through the copula is graphically presented in Fig. 7.

Serial dependence is especially categorized by using tail-symmetric copulas such as Student's $t$, Frank, and Gaussian. However, it is commonly non-Gaussian and reveals heavy joint tails as inferred by way of Student's $t$ copula. However, the firstorder serial dependence of domestic gasoline price is decided through the heavytail-based Gumbel copula: the predicted version implied higher tail dependence 
Table 2 Selected Copulas and their estimated parameters of the COPAR (1) model, where Gasoline price(G.P.) narrate to $\left\{X_{t}\right\}$

\begin{tabular}{|c|c|c|c|c|c|}
\hline & $C_{0}^{X Y}$ & $C_{1}^{X}$ & $C_{1}^{X Y}$ & $C_{1}^{Y X}$ & $C_{1}^{Y}$ \\
\hline COPAR(K) & RT-I & $\mathrm{N}$ & $\mathrm{N}$ & $\mathrm{t}$ & G \\
\hline \multicolumn{6}{|l|}{ IFIGP } \\
\hline Parameters & $(1.88,0.22)$ & 0.25 & 0.07 & 0.13 & 2.01 \\
\hline Degrees of freedom & & & & 15 & \\
\hline Kendall's $\tau$ & 0.27 & 0.19 & 0.11 & 0.09 & 0.59 \\
\hline IRIGP & RT-I & $\mathrm{F}$ & $\mathrm{t}$ & $\mathrm{F}$ & G \\
\hline Parameters & $(4.74,0.29)$ & 15.42 & 0.15 & 1.33 & 1.77 \\
\hline Degrees of freedom & & & 7 & & \\
\hline Kendall's $\tau$ & 0.19 & 0.77 & 0.28 & 0.17 & 0.43 \\
\hline IPIGP & $\mathrm{N}$ & $\mathrm{t}$ & $\mathrm{N}$ & $\mathrm{t}$ & G \\
\hline Parameters & 0.17 & 0.41 & -0.24 & -0.13 & 1.88 \\
\hline Degrees of freedom & & 8 & & 11 & \\
\hline Kendall's $\tau$ & 0.11 & 0.27 & -0.17 & -0.08 & 0.47 \\
\hline
\end{tabular}

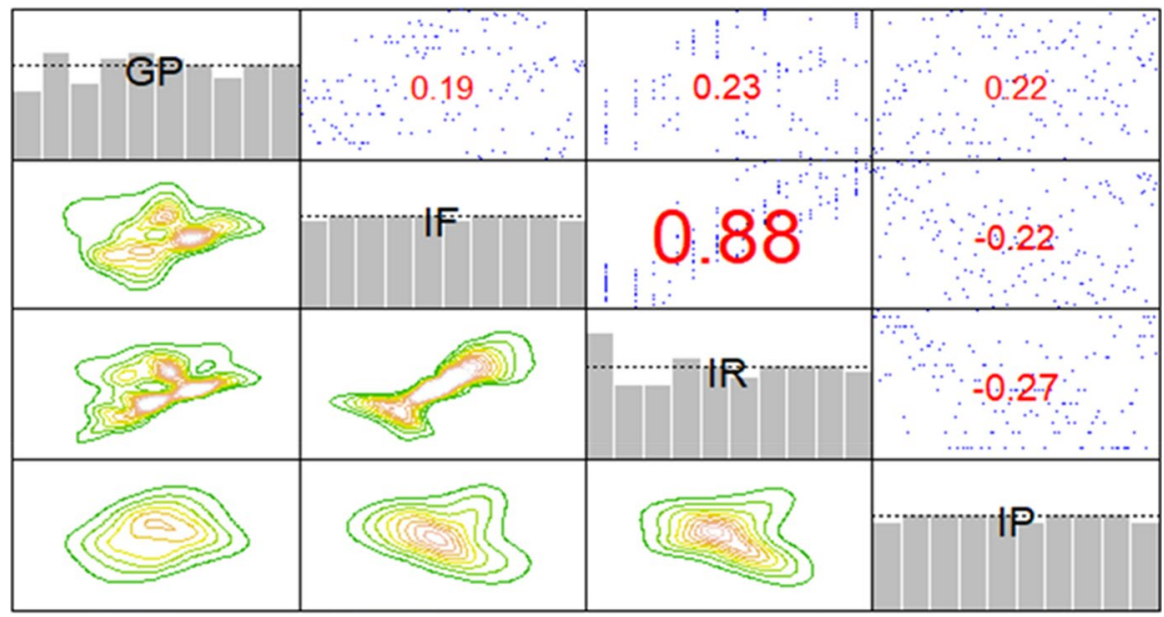

Fig. 7 Copula Dependence of Gasoline price (G.P.) with other economic variables

coefficient is set at 0.59 . That is, there may be a greater opportunity of successive high rates than of two low ones.

For between-series reliance, the designated copulas show a comparable appearance: while the maximum reliance is tail-symmetric, there are clear deviations from symmetry. The dependence between fuel price and interest rate is mostly partially laid out in terms of $t$-copulas with tail-symmetric dependence. Interestedly, the (restrictive) first lag dependence of gasoline price on commercial production and interest rate is more effective than the immediate one. Thus, the standard influence of adjustments within the fuel price on those variables is not on the time employing one month, whereas the inflation price reacts faster. 


\section{Concluding and Implications}

For a very lengthy time, the oil prices and inflation rates have been closely related. When the valuable black liquid's price goes up, an upward trend has been observed in the inflation rate. The reason for that is because oil is an excellent commodity that's associated with a variety of factors. Oil is used to warm houses, strengthen public utilities, as well as run factories; it is also an immediate component in things like plastics. That being said, if the input rate for oil rises, so will the prices of completed commodities and offerings.

If an economist can determine the interrelationship between macroeconomic variables and the effects of exogenous variables on these indicators, this contributes drastically to monetary and political balance. This research applies copula to model the dependence of inflation, industrial production, and the interest rate on gasoline price. More precisely, we look at the autoregressive copula model to model the reliance structure of some of the economic variables in the country, which ends up in a non-Gaussian reliance amongst variables. The underline demonstrating method is convenient to model nonlinear dependence amongst numerous time series, in particular, to analyze the effect of several time-varying variables on a time series playing a key role. Taking advantage of COPAR-model, we study domestic oil price outcomes on inflation, interest rate and commercial manufacturing in Pakistan.

Moreover, we finished the Granger causality assessment to look at the causality relation between the variables. Inside the evaluation, we come across the handiest weak tail asymmetries; however, a few tail dependences. Furthermore, the models' display screen lagged in industrial production and interest rate adjustments in the domestic oil rate. The oil price impact on the inflation rate, on the other hand, is alternatively instantaneous.

Our foremost contribution is implementing the autoregressive copula model of Brechmann and Czado (2015) to model the reliance structure of vital timevarying variables. This is the addition of a new technique to the existing literature and enables us to investigate the hidden dependence among economic indicators more precisely. Micro-monetary indicators, which comprise inflation, gold rate, exchange rate, interest rate, inventory returns, oil price, and foreign reserves, are of superb significance; as a relation among oil expenses, inflation, interest rate and industrial manufacturing may be beneficial not most effective for foreign and domestic consumers but for authorities as well, the relation among gasoline price and inflation rate may be a guideline for authorities; in order a whole it will be useful for policymakers to formulate regulations and to take measures to limit the daring effects of higher/lower of fuel prices and inflation rate on the monetary system.

In the future, conventional variables such as gold price, stock returns, overseas reserves, gross domestic product, etc. must additionally be brought alongside important progressive variables; its far going to be helpful to discover which variable is imputable for extra variation in inflation rate and the based structure amongst them may be explored. Those points are subject to future studies. 


\section{Appendix 1: Variables and their description}

In the following table, SBP stands for State Bank of Pakistan, PBS stands for Pakistan Bureau of Statistics, and PSO stands for Pakistan State Oil (Table 3).

Table 3 Pakistan Micro-Economic Indicators

\begin{tabular}{llll}
\hline Indicator & Description & Transformation & Source \\
\hline Gasoline Prices & Gasoline Price in Pakistan USD/litre & Monthly & PSO \\
Inflation Rate & Inflation rate in the country & Monthly & PBS \\
Interest Rate & The interest rate in the country decided by SBP & Monthly & SBP \\
Industrial Production & Commercial production in the country & Monthly & SBP \\
\hline
\end{tabular}

\section{Appendix 2}

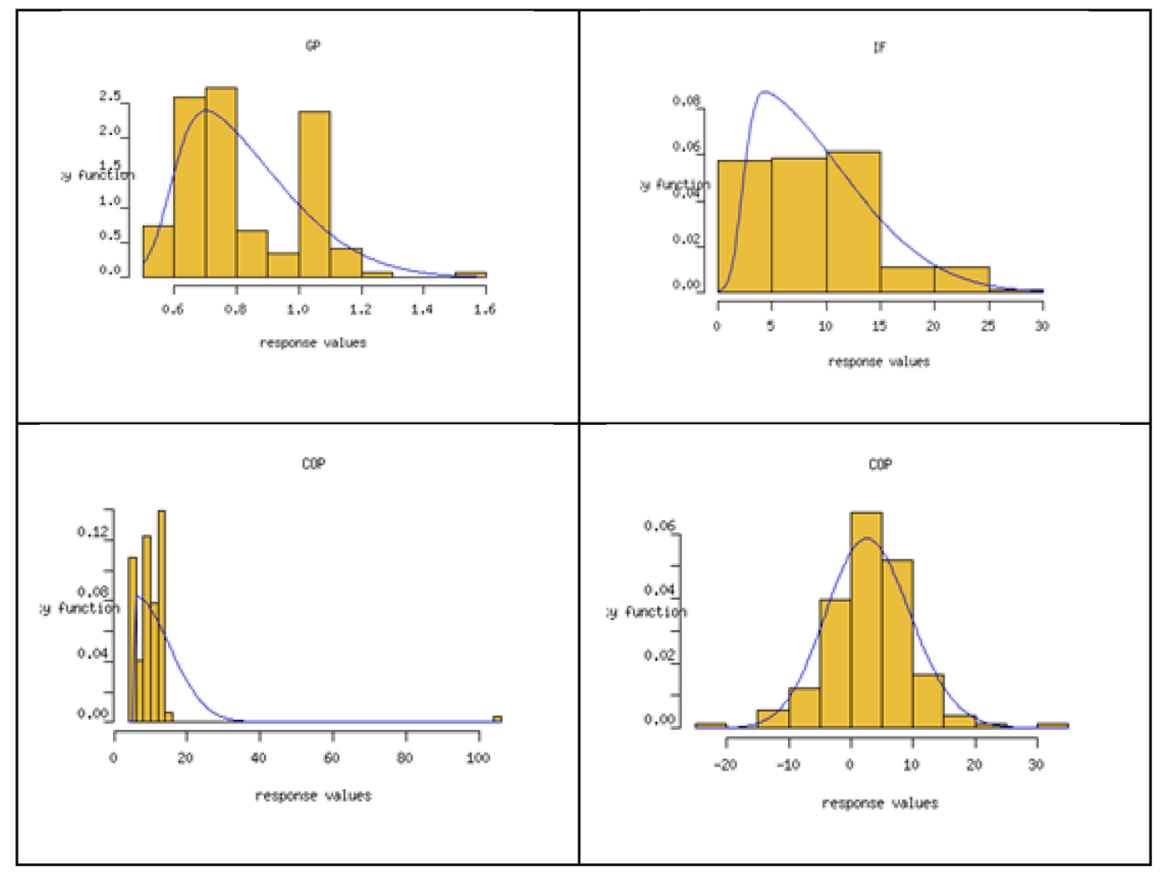




\section{Appendix 3: Causality Test}

See Table 4.

Table 4 Granger-test summary of simple regression

\begin{tabular}{|c|c|c|c|c|}
\hline & \multicolumn{4}{|l|}{ Dependent variables } \\
\hline & $G_{t}$ & $I_{t}$ & $R_{t}$ & $P_{t}$ \\
\hline$G_{t-1}$ & $0.6004 * *(0.2142)$ & $5.13848(6.2199)$ & $6.964(7.0301)$ & $6.4343(6.963)$ \\
\hline$I_{t-1}$ & $-0.0190(0.0128)$ & $0.44047(0.37)$ & $0.779 *(0.420)$ & $0.2990(0.4163)$ \\
\hline$R_{t-1}$ & $-0.0003(0.0014)$ & $-0.00839(0.0413)$ & $0.49 * * *(0.046)$ & $0.0053(0.046)$ \\
\hline$P_{t-1}$ & $-0.00084(0.0024)$ & $-0.02008(0.455)$ & $-0.01382(0.0794)$ & $0.49392 * * *(0.078)$ \\
\hline Constant & $\begin{array}{r}0.8245 * * * \\
(0.0024)\end{array}$ & $\begin{array}{l}9.26816 * * * \\
(0.455)\end{array}$ & $\begin{array}{r}10.4344 * * * \\
(0.51472)\end{array}$ & $\begin{array}{l}2.966613 * * * \\
(0.509)\end{array}$ \\
\hline $\begin{array}{l}\text { F Statistics } \\
\qquad(\mathrm{df}=4,141)\end{array}$ & $2.289 * *(0.001)$ & $0.6512 *(0.027)$ & $30.3 * * *(0.0011)$ & $10.4 * * *(0.000)$ \\
\hline P-value & 146 & 146 & 146 & 146 \\
\hline \multicolumn{5}{|l|}{ No. of Obs } \\
\hline$R^{2}$ & 0.0609 & 0.01814 & 0.4622 & 0.2279 \\
\hline $\operatorname{Adj} . R^{2}$ & 0.03434 & -0.009717 & 0.4469 & 0.206 \\
\hline $\begin{array}{l}\text { Resid.S.E } \\
\qquad(\mathrm{df}=141)\end{array}$ & 0.1895 & 5.502 & 6.218 & 6.16 \\
\hline
\end{tabular}

$*$ Represents significant at $10 \%, * *$ at $5 \%$ and $* * * 1 \%$

\section{Appendix 4: Copulas}

See Table 5.

Table 5 Families and their Order as per Vine Copula R-package

\begin{tabular}{ll}
\hline Order & Family \\
\hline 0 & independence copula \\
1 & Gaussian copula \\
2 & Student t copula (t-copula) \\
3 & Clayton copula \\
4 & Gumbel copula \\
5 & Frank copula \\
6 & Joe copula \\
13 & Survival Clayton \\
104 & Tawn type 1 copula \\
114 & Rotated Tawn type 1 copula $\left(180^{\circ}\right)$ \\
\hline
\end{tabular}


Acknowledgements The authors acknowledge the financial supports from National Science Foundation, Pakistan (G. no. 179875).

\section{Author contributions NA.}

Funding This research was supported by National Science Foundation of Pakistan (Grant no. 179875).

Availability of data and material All results reported in this research was carried out in R-studio computational environment.

\section{Declarations}

Conflict of interest The author declares no competing interest.

Ethics approval and consent to participate This article does not contain any studies with human participants or animals performed by any of the authors.

\section{References}

Aas, Kjersti. 2016. Pair-copula constructions for financial applications: A review. Econometrics 4: 43.

Aas, Kjersti, Claudia Czado, Arnoldo Frigessi, and Henrik Bakken. 2009. Pair-copula constructions of multiple dependence. Insurance: Mathematics and Economics 44: 182-198.

Akbar, M., F. Iqbal, and F. Noor. 2019. Bayesian analysis of dynamic linkages among gold price, stock prices, exchange rate and interest rate in Pakistan. Resources Policy 62: 154-164.

Aslam, W. 2014. Relationship between stock market volatility and exchange rate: A study of KSE. Journal of Public Administration, Finance and Law 5: 62-72.

Azzalini, A. 1985. A class of distributions which includes the normal ones. Scandinavian Journal of Statistics 12: 171-178.

Beare, Brendan K., and Juwon Seo. 2015. Vine copula specifications for stationary multivariate Markov chains. Journal of Time Series Analysis 36: 228-246.

Brechmann, Eike Christian, and Claudia Czado. 2015. COPAR_-Multivariate time series modeling using the copula autoregressive model. Applied Stochastic Models in Business and Industry 31: 495-514.

Czado, Claudia. 2010. Pair-copula constructions of multivariate copulas. In Copula Theory and Its Applications, ed. Wolfgang Härdle, Piotr Jaworski, and Tomasz Rychlik, 93-109. New York: Springer.

Czado, Claudia, Eike Christian Brechmann, and Lutz Gruber. 2012a. Selection of vine copulas. In Copulae in Mathematical and Quantitative Finance, ed. Fabrizio Durante and Piotr Jaworski, 17-37. New York: Springer.

Czado, Claudia, Ulf Schepsmeier, and Aleksey Min. 2012b. Maximum likelihood estimation of mixed C-vines with application to exchange rates. Statistical Modelling 12: 229-255.

Dawson, J. C. 2007. The Effect of Oil Prices on Exchange Rates: A Case Study of the Dominican Republic Undergraduate Economic Review. 3: Article 4

Dissmann, Jeffrey, Eike Christian Brechmann, Claudia Czado, and Dorota Kurowicka. 2013. Selecting and estimating regular vine copulae and application to financial returns. Computational Statistics \& Data Analysis 59: 52-69.

Hussain, M.Y.M., F. Muhammad, A.A. Razak, G.P. Tha, and N. Marwan. 2013. The link between gold price, oil price and Islamic stock market: Experience from Malaysia. Journal of Studies in Social Sciences 4 (2): 161-182.

Irshad, H., G.A. Bhatti, A. Qayyum, and H. Hussain. 2012. Long run relationship among oil, gold and stock prices in Pakistan. Journal of Commerce 6 (4): 06-21.

Ito, K. 2010. The impact of oil price volatility on macroeconomic activity in Russia. Economic Analysis Working Papers 9: 1-21.

Jain, A., and P.C. Biswal. 2016. Dynamic linkages among oil price, gold price, exchange rate, and stock market in India. Resource Policy 49: 179-185.

Jain, A., and S. Ghosh. 2013. Dynamics of global oil prices, exchange rate and precious metal prices in India. Resource Policy 38 (1): 88-93. 
Kurowicka, Dorota, and Roger Cooke. 2006. Uncertainty analysis with high dimensional dependence modelling. New York: Wiley.

Morales-Nápoles, Oswaldo, Roger Cooke and Dorota Kurowicka. 2010. About the number of vines and regular vines on $n$ nodes. https://doi.org/10.13140/RG.2.1.4400.8083

Mushtaq, M., S. Zulfiqar Ali Shah, and Rehman Ziaur. 2012. The relationship between stock market volatility and macroeconomic volatility: evidence from Pakistan. African Journal of Business Management. 6 : 7387-7396.

Oh, Dong Hwan, and Andrew J. Patton. 2017. Modelling dependence in high dimensions with factor copulas. Journal of Business \& Economic Statistics 35: 139-154.

Patton, A.J. 2006. Modelling asymmetric exchange rate dependence. International Economic Review 47 (2): 527-556.

Sari, R., S. Hammoudeh, and U. Soytas. 2010. Dynamics of oil price, precious metal prices, and exchange rate. Energy Economics 32 (2): 351-362.

Smith, Michael Stanley. 2015. Copula modelling of dependence in multivariate time series. International Journal of Forecasting 31: 815-833.

Stöber, Jakob, Harry Joe, and Claudia Czado. 2013. Simplified pair copula constructions-limitations and extensions. Journal of Multivariate Analysis 119: 101-118.

Tabassum, S., and S. Gulzar. 2015. Dynamic relation between macroeconomic variables and exchange rate in Pakistan. Science Internaional (lahore) 27 (3): 2431-2436.

Vuong, Q.H. 1989. Ratio tests for model selection and non-nested hypotheses. Econometrica 57 (2): 307-333.

Publisher's Note Springer Nature remains neutral with regard to jurisdictional claims in published maps and institutional affiliations. 